\title{
Effects of different drying conditions on curcumin concentration in turmeric
}

\author{
Li, Q.; Driscoll, R.; Srzednicki, G. *
}

School of Chemical Engineering, The University of New South Wales, Sydney 2052, Australia

*E-mail of the corresponding author: georgesrz@yahoo.com

\begin{abstract}
Turmeric (Curcuma longa), belongs to Zingiberaceae family. The rhizomes contain bioactive compounds of the curcuminoids group (natural phenols). They are used in food and pharmaceutical industry. The aim of this research was to acquire dried turmeric with high total curcumin content. In this study, optimum turmeric drying conditions and new extraction techniques were explored. Fresh turmeric samples were subjected to constant vs changing drying air temperatures and pre-treatment (blanching). Changing drying air temperature and use of non-blanched turmeric slices resulted in the highest concentration of curcumin. Ultrasonic extraction instead of soxhlet extraction improved the extraction efficiency and decreased extraction time.
\end{abstract}

Keywords: Turmeric, Curcumin; Drying; Blanching; Extraction 


\section{Introduction}

Turmeric, known as Curcuma longa, belongs to the Zingiberaceae family like ginger and cardamom. It is an erect perennial herb which has a short stem with large oblong leaves and produces ovate, pyriform or oblong rhizomes. The rhizomes may have many branches and are of brownish-yellow colour. The aroma of turmeric is musky, pepper-like and the flavour is slightly aromatic, bitter. The colour of dried turmeric varies from orange brown to pale yellow or reddish yellow. The main compounds responsible for these properties are curcuminoids that include curcumin, demethoxycurcumin and bis-demethoxycurcumin. They are mainly extracted from dried turmeric. Curcuminoids are natural phenols and produce a pronounced yellow colour. They are popular as pigments in food industry that uses turmeric oleoresin as the starting material. The rhizome of turmeric is an important raw material to extract curcumin that contains $3.1 \% \sim 10 \%$. The dried rhizome contains $45 \% \sim 50 \%$ starch, $40 \% \sim 50 \%$ cellulose $^{[1]}$. They are also well known for their pharmaceutical and nutritional properties, particularly as anti-oxidants. The pharmaceutical properties include anticancer, antibacterial, anti-infective and insecticidal effect.

In turmeric powder manufacturing, dehydration is an important process step since the water activity can be reduced by drying so that the growth and reproduction of food spoilage microbial can be inhibited by passivating the food enzymes which would cause adverse chemical reactions ${ }^{[2]}$. Thereby it helps extend the shelf life of food and reach the preservation goals. However, different drying conditions may affect the amount of curcumin content in turmeric powder. Thus, the curcumin should be extracted after drying and the concentration of curcumin can be detected by using HPLC measuring method at $425 \mathrm{~nm}$ wavelength. There are several extraction methods for curcumin including soxhlet.

The aim of this research was to acquire dried turmeric with high total curcumin content. In this study, optimum turmeric drying conditions and new extraction techniques have been explored before quantitating the curcumin in dried rhizomes by HPLC.

\section{Materials and Methods}

\subsection{Turmeric Samples}

\subsubsection{Sample Procurement}

Matured, healthy and fresh turmeric rhizomes were supplied by Earthcare Enterprises located in Maleny on Queensland's Sunshine Coast Hinterland. They were refrigerated and transported in a thermally insulated container to the University of NSW laboratory in Sydney. Once in the laboratory, they were placed in zip bags made from polyethylene film and kept in a freezer at $-20{ }^{\circ} \mathrm{C}$ until needed for experiments. 


\subsubsection{Sample preparation}

The frozen turmeric samples were removed from the freezer and left overnight in a refrigerator at $+4{ }^{\circ} \mathrm{C}$. after procurement.

For each drying run, around $70 \mathrm{~g}$ of rhizomes were weighed and peeled to obtain around 50 $\mathrm{g}$ of peeled rhizomes that were either quartered or sliced (slices $5 \mathrm{~mm}$ thick).

\subsubsection{Blanching}

Some of the quartered samples were blanched in $70^{\circ} \mathrm{C}$ water bath for different times $(5,15$ and 30 minutes). After blanching, the samples were dipped into ice cold water directly for 1 minute and then left for 10 minutes to allow the water to drip off

\subsubsection{Moisture content determination}

The moisture content in the fresh and also in the dried slices was determined following the AOAC Official Method $934.06^{[3]}$. Triplicate samples of of turmeric (5 g) were dried in a convection oven at $110^{\circ} \mathrm{C}$ for 6 hours.

\subsection{Drying experiments}

\subsubsection{Dryer}

The drying experiments were carried out in a cabinet dryer designed in the workshop of the School of Chemical Engineering of the University of New South Wales. The cabinet dryer (see Fig. 1) has an electric heater $(15 \mathrm{~kW})$ fitted with a PID controller and a fan $(0.75 \mathrm{~kW})$. The airflow is parallel to the tray on which the drying samples are placed in a thin layer. The temperature and relative humidity were monitored and recorded with a datalogger. The weight loss was recorded with an electronic balance placed under the samples holding tray.

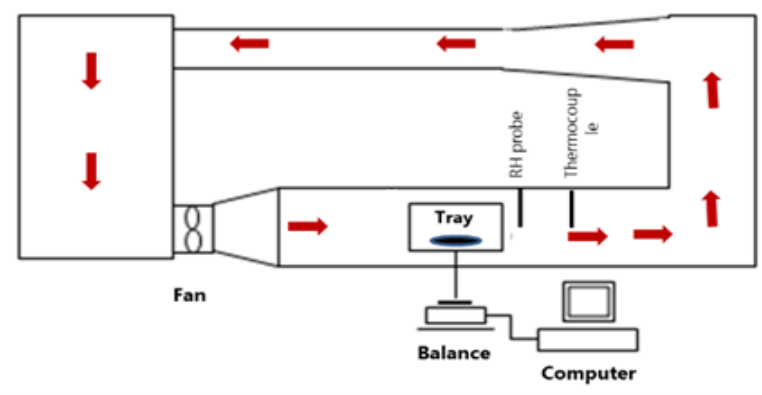

Fig. 1 Cabinet dryer. 


\subsubsection{Drying conditions}

The drying conditions were defined either by a constant temperature or a changing temperatue (see Table 1). The reason for choosing the drying temperatures in the range 40$60{ }^{\circ} \mathrm{C}$ was that this corresponds to temperatures used by the industry including solar drying. Including changing conditions within this temperature range in addition to constant conditions was aiming at exploring the possibility of increasing the curcumin recovery.

Table 1. Drying conditions for experiments

\begin{tabular}{lcclc}
\hline Run & Temperature $\left(\mathbf{~}^{\mathbf{C}}\right)$ & RH (\%) & Shape & Blanching (min) \\
\hline 1 & 40 & 20 & quartered & 0 \\
2 & 40 & 20 & sliced & 0 \\
3 & 50 & 10 & quartered & 0 \\
4 & 50 & 10 & sliced & 0 \\
5 & 50 & 20 & quartered & 0 \\
6 & 55 & 12 & quartered & 0 \\
7 & 55 & 12 & sliced & 0 \\
8 & 60 & 10 & quartered & 0 \\
9 & 60 & 10 & sliced & 0 \\
10 & 60 & 20 & quartered & 0 \\
11 & 60 & 20 & sliced & 0 \\
12 & 60 & 10 & quartered & 5 \\
13 & 60 & 10 & quartered & 15 \\
14 & 60 & 10 & quartered & 30 \\
15 & $60-50$ & 20 & sliced & 0 \\
16 & $50-60$ & 20 & sliced & 0 \\
17 & $60-40$ & 20 & sliced & 0 \\
18 & $40-60$ & 20 & sliced & 0 \\
19 & $50-40$ & 20 & sliced & 0 \\
20 & $40-50$ & 20 & sliced & 0 \\
\hline & & & & \\
\hline
\end{tabular}

\subsection{Curcumin determination}

\subsubsection{Extraction}

A sample of dried turmeric ( $5 \mathrm{~g}$ ) was ground for $1 \mathrm{~min}$ in the Single-phase Resis Tanlestart Grinder (Shanghai Rihui Electrical Machinery Co). Each ground sample was passed through a sieve (250 $\mu \mathrm{m}$ size).

The powder sample (1.00 g) from each drying treatment was placed in a centrifuge tube (medical grade polypropylene) tube. An aliquot of $15 \mathrm{~mL} \mathrm{100 \%} \mathrm{ethanol} \mathrm{(HPLC} \mathrm{grade)} \mathrm{was}$ added into each tube and mixed. Then the tubes were closed with a cap and sonicated for 1 
hour at $55{ }^{\circ} \mathrm{C}$. After sonication, the tubes should be covered with an aluminium foil and vortexed for $1 \mathrm{~h}$ at room temperature. Then, all samples should be diluted by mixing 750 $\mu \mathrm{L}$ of extraction solution with $750 \mu \mathrm{L}$ of $100 \%$ ethanol (HPLC grade) and then filtered.

\subsubsection{Quantitation by HPLC}

The solvents used in the quantitation work were as follows: 100\% ethanol (HPLC grade) manufactured by Merck Pty Ltd; acetic acid (HPLC grade) manufactured by VWR; acetonitrile (HPLC grade) manufactured by VWR; Milli-Q Water (HPLC grade).

The curcumin analytical standard was obtained from Fluka.

HPLC detection was performed by applying a Shimadzu-LC system (Shimadzu, Japan) including an LC-20AD liquid chromatograph, a SIL-20A HT auto sampler (auto-injector), a CBM-20A communications bus module (UV-VIS detector), LC Solution software and the Xterra C18 Column (MS 3.5 m; length: 150 mm; diameter: $2.1 \mathrm{~mm}$, Waters, Ireland).

The HPLC assay was implemented in a reverse-phase by using an isocratic elution with a total flow rate of $0.1500 \mathrm{~mL} / \mathrm{min}$, a column oven temperature of $30{ }^{\circ} \mathrm{C}$; a mobile phase of $2 \%$ acetic acid and $100 \%$ acetonitrile (60:40); a detection wavelength of $425 \mathrm{~nm}$ for curcumin. The injection volume was $20 \mu \mathrm{L}$. All solutions were filtered by using the glass vacuum filtration apparatus and accessories with filter membrane (hydrophilic PTFE with $0.45 \mu \mathrm{m}$ pore size) under the fume cupboard prior to HPLC injection. The total time for testing was $10 \mathrm{~min}$ for each sample.

Standard solutions of curcumin in pure ethanol were prepared separately from the stock solution with the concentration of $1000 \mu \mathrm{g} / \mathrm{mL}$ that was diluted with $100 \%$ ethanol to obtain concentrations of $20 \mu \mathrm{g} / \mathrm{mL}, 30 \mu \mathrm{g} / \mathrm{mL}, 40 \mu \mathrm{g} / \mathrm{mL}, 50 \mu \mathrm{g} / \mathrm{mL}, 60 \mu \mathrm{g} / \mathrm{mL}, 70 \mu \mathrm{g} / \mathrm{mL}$ of standard solutions. A calibration curve was produced on the basis of the values obtained.

\section{Results and discussion}

\subsection{Moisture content}

The samples were dried until a constant weight of the sample was obtained, i. e. had to remain unchanged during at least three consecutive readings. This corresponded to the equilibrium moisture content for a given set of drying conditions (temperature and RH).

The drying runs 1-4 and 6-11 were set up to compare different effects of the sample shape (sliced vs. quartered) on the equilibrium moisture content of dried samples. It appears that at drying air temperatures of 40,50 and $55^{\circ} \mathrm{C}$ at any of the three $\mathrm{RH}$ values $(10,12$ or $20 \%$ ), the quartered samples had a higher mosture content. However, at $60{ }^{\circ} \mathrm{C}$ there was no difference in the final moisture content between the different shapes of cut turmeric 
rhizomes. As for runs 12-14 it appears that there was no effect of blanching time on the final moisture content. Finally, the runs 15-20 are showing the effects of drying conditions on the final mosture content. It appears that in all six runs the procedure of starting with the higher drying temperature and then changing it to lower one $\left(60^{\circ} \mathrm{C}\right.$ to $40^{\circ} \mathrm{C}$ vs $40{ }^{\circ} \mathrm{C}$ to 60 $\left.{ }^{\circ} \mathrm{C}\right)$ resulted in a higher final moisture content.

Table 2. Average equilibrium moisture content for each run

\begin{tabular}{|c|c|c|c|}
\hline $\begin{array}{c}\text { Run } \\
\text { Number }\end{array}$ & Run conditions & $\begin{array}{c}\text { Equilibrium } \\
\text { Moisture } \\
\text { Content (\% db) }\end{array}$ & $\begin{array}{c}\text { Drying } \\
\text { time (min) }\end{array}$ \\
\hline 1 & $40^{\circ} \mathrm{C} 20 \% \mathrm{RH}$ (quartered) & 7.50 & 220 \\
\hline 2 & $40^{\circ} \mathrm{C} 20 \% \mathrm{RH}$ (sliced) & 7.29 & 196 \\
\hline 3 & $50^{\circ} \mathrm{C} 10 \% \mathrm{RH}$ (quartered) & 4.40 & 243 \\
\hline 4 & $50{ }^{\circ} \mathrm{C} 10 \% \mathrm{RH}$ (sliced) & 4.32 & 147 \\
\hline 5 & $50{ }^{\circ} \mathrm{C} 20 \% \mathrm{RH}$ (quartered) & 5.65 & 204 \\
\hline 6 & $55^{\circ} \mathrm{C} 12 \% \mathrm{RH}$ (quartered) & 3.69 & 188 \\
\hline 7 & $55^{\circ} \mathrm{C} 12 \% \mathrm{RH}$ (sliced) & 3.44 & 145 \\
\hline 8 & $60{ }^{\circ} \mathrm{C} 10 \% \mathrm{RH}$ (quartered) & 2.49 & 247 \\
\hline 9 & $60{ }^{\circ} \mathrm{C} 10 \% \mathrm{RH}$ (sliced) & 2.51 & 157 \\
\hline 10 & $60{ }^{\circ} \mathrm{C} 20 \% \mathrm{RH}$ (quartered) & 4.59 & 202 \\
\hline 11 & $60{ }^{\circ} \mathrm{C} 20 \% \mathrm{RH}$ (sliced) & 4.58 & 187 \\
\hline 12 & $60{ }^{\circ} \mathrm{C} 10 \% \mathrm{RH}$ (quartered, blanched $5 \mathrm{~min}$ ) & 2.48 & 272 \\
\hline 13 & $60{ }^{\circ} \mathrm{C} 10 \% \mathrm{RH}$ (quartered, blanched $15 \mathrm{~min}$ ) & 2.52 & 272 \\
\hline 14 & $60{ }^{\circ} \mathrm{C} 10 \% \mathrm{RH}$ (quartered, blanched $30 \mathrm{~min}$ ) & 2.51 & 280 \\
\hline 15 & $60{ }^{\circ} \mathrm{C} 20 \% \mathrm{RH}$ to $50^{\circ} \mathrm{C} 20 \% \mathrm{RH}$ (sliced) & 5.54 & 176 \\
\hline 16 & $50{ }^{\circ} \mathrm{C} 20 \% \mathrm{RH}$ to $60{ }^{\circ} \mathrm{C} 20 \% \mathrm{RH}$ (sliced) & 4.81 & 192 \\
\hline 17 & $60^{\circ} \mathrm{C} 20 \% \mathrm{RH}$ to $40^{\circ} \mathrm{C} 20 \% \mathrm{RH}$ (sliced) & 6.76 & 186 \\
\hline 18 & $40{ }^{\circ} \mathrm{C} 20 \% \mathrm{RH}$ to $60^{\circ} \mathrm{C} 20 \% \mathrm{RH}$ (sliced) & 5.28 & 177 \\
\hline 19 & $50{ }^{\circ} \mathrm{C} 20 \% \mathrm{RH}$ to $40{ }^{\circ} \mathrm{C} 20 \% \mathrm{RH}$ (sliced) & 7.21 & 299 \\
\hline 20 & $40{ }^{\circ} \mathrm{C} 20 \% \mathrm{RH}$ to $50{ }^{\circ} \mathrm{C} 20 \% \mathrm{RH}$ (sliced) & 5.95 & 264 \\
\hline
\end{tabular}

\subsection{Curcumin content}

With regard to the effect of $\mathrm{RH}$ during drying of sliced non-blanched rhizomes at $60{ }^{\circ} \mathrm{C}$ it was found that sample from run 11 exposed to $20 \% \mathrm{RH}$ had a $23 \%$ higher curcumin concentration (3.53 mg/g dry matter) than sample from run 9 (2.86 mg/g dry matter).

As for the effect of of the drying temperature at the same RH (20\%), during drying of sliced non-blanched rhizomes, it is found that sample from run 2 had a $13 \%$ higher concentration of curcumin (3.99 mg/g dry matter) than sample 11 (3.53 mg/g dry matter). The drying 
temperature of samples 2 and 11 was $40^{\circ} \mathrm{C}$ and $60^{\circ} \mathrm{C}$, respectively. The same phenomenon was observed when comparing the effects of drying air temperature on the curcumin content in quartered rhizome samples, see samples 1 (3.86 mg/g dry matter) vs. sample 10 (2.86 mg/g dry matter) and sample 5 (2.81 mg/g dry matter) dried at $40{ }^{\circ} \mathrm{C}, 60{ }^{\circ} \mathrm{C}$ and 50 ${ }^{\circ} \mathrm{C}$, respectively. Hence, it can be considered that a lower drying temperature leads to a higher curcumin content.

Table 3. Curcumin content in dried samples

\begin{tabular}{ccc}
\hline $\begin{array}{c}\text { Run } \\
\text { number }\end{array}$ & $\begin{array}{c}\text { Weight of curcumin extracted } \\
\left.\text { from dried samples }(\boldsymbol{\mu g})^{\text {a }}\right)\end{array}$ & $\begin{array}{c}\text { Curcumin concentration on dry } \\
\text { matter basis }(\mathbf{m g} / \mathbf{g} \text { dry matter) }\end{array}$ \\
\hline 1 & 1.24 & 3.86 \\
2 & 1.97 & 3.99 \\
3 & 1.08 & 2.70 \\
4 & 1.67 & 3.33 \\
5 & 1.39 & 2.81 \\
6 & 1.57 & 3.82 \\
7 & n.a. $\left.{ }^{\mathrm{b}}\right)$ & n.a. \\
8 & 1.27 & 2.49 \\
9 & 1.69 & 2.86 \\
10 & 1.25 & 2.88 \\
11 & 1.88 & 3.53 \\
12 & 1.30 & 2.37 \\
13 & 1.42 & 3.27 \\
14 & 1.68 & 3.72 \\
15 & 1.26 & 3.04 \\
16 & 1.39 & 3.32 \\
17 & 1.09 & 6.95 \\
18 & 1.22 & 3.70 \\
19 & 1.80 & 4.01 \\
20 & 1.52 & 4.96 \\
\hline
\end{tabular}

a) Total weight of curcumin extracted from entire dried sample; ${ }^{\text {b }}$ ) n.a. = data not available

With regard to the difference between quartered and sliced samples, the comparison of results from runs 1 vs 2, 3 v 4 and 10 vs 11 shows clearly that the dried quartered samples had a lower curcumin content.

Finally, with regard to the effects of changing conditions on the curcumin content, they resulted generally in a higher concentration than constant conditions.

In this experiment, ultrasonic extraction was used in extraction instead of traditional soxhlet extraction. The time of ultrasonic extraction was $1 \mathrm{~h}$. It was determined after comparing the 
sonication at $55{ }^{\circ} \mathrm{C}$ for $15 \mathrm{~min}, 30 \mathrm{~min}$ and 1 hour. It is found that there was no peak at 425 nm wavelength times of less than 1 hour. This extraction method is reported to strength extraction efficiency and decrease extraction time ${ }^{[4]}$. The use of sonication had a significant advantage over the conventional soxhlet extraction taking several hours.

\section{Conclusions}

This study compares the concentration of curcumin in samples of dried turmeric rhizomes subjected to different drying treatments. It has been found that the changing conditons and use of of non-blanched sliced turmeric rhizome dried at $40{ }^{\circ} \mathrm{C}$ and $20 \% \mathrm{RH}$ yielded $3.99 \mathrm{mg}$ curcumin/g dry matter which was higher than in any other sample dried under constant conditions. In comparison, the changing conditions resulted in higher curcumin content. Moreover, blanching would generally lead to a higher concentration of curcumin in the dried samples. Finally, 20\% RH led to a higher concentration of curcumin than $10 \%$ RH.

\section{Nomenclature}

RH relative humidity $\quad \%$

\section{References}

[1] Burnham T.H. 'Review of natural products'. St. Louis: Facts and Comparisons. 1993, 38(22): pp. 23-26

[2] Adhami S, Rahimi A, Hatamipour MS,. 'Freeze drying of quince (Cydonia oblonga): Modelling of drying kinetics and characteristics'. Korean Journal of Chemical Engineering 2013, 30(6), 1201-1206.

[3] AOAC. Official methods of analysis (Vol. 534). W. Horwitz (Ed.). Association of Official Analytical Chemists, Washington, DC, 2006.

[4] Dhanalakshmi N. P, Nagarajan R,. World Academy of Science, Engineering and Technology 2011, 5: pp.11-29. 